\title{
PERALATAN PRESS HIDROLIK SEBAGAI SOLUSI PENGOLAHAN GAMBIR DI SUMATERA BARAT
}

\section{HYDRAULIC PRESS MACHINE AS A SOLUTION FOR GAMBIER PROCESSING IN WEST SUMATRA}

\author{
Amos Lukas ${ }^{1}$, Suharto Ngudiwaluyo ${ }^{1}$, Ira Nurhayati Djarot ${ }^{1}$, \\ R. Djoko Goenawan ${ }^{2}$ dan Heru Mulyono ${ }^{3}$ \\ ${ }^{1}$ Pusat Sistim Audit Teknologi, BPPT, JI.MH. Thamrin No. 8 Jakarta \\ ${ }^{2}$ Balai Besar Teknologi Modifikasi Cuaca, BPPT, Jl. MH Thamrin No 8, Jakarta \\ ${ }^{3}$ Pusat Teknologi Kawasan Spesifik dan Sistem Inovasi, BPPT, JI.MH. Thamrin No. 8 Jakarta \\ 1 e-mail : amoslukas2010@gmail.com
}

Diterima: 16 Juli 2018; Direvisi: 19 Juli 2019 - 08 Juni 2020; Disetujui: 17 Juni 2020

\begin{abstract}
Abstrak
Pengolahan gambir di Sumatera Barat pada awalnya menggunakan peralatan Kampo dalam mengekstrak gambir, peralatan kampo banyak menguras tenaga pekerja, pengolahan dalam sehari maksimum 4 kali, dengan rendemen gambir 8-9 \%, dalam sehari hanya mampu produksi gambir sebesar $14 \mathrm{~kg}-16 \mathrm{~kg}$. Rekayasa peralatan hidrolik pres gambir bertujuan agar pekerja tidak terlalu menguras tenaga, pengolahan dapat dilakukan lebih dari 20 kali, dengan rendeman di atas $10 \%$. Peralatan hidrolik pres gambir dirancang menggunakan bahan plat H Frame dari bahan baja merupakan hasil inovasi untuk meringankan tenaga kerja, mempercepat proses pengolahan, menghasilkan produk gambir yang konstan mutunya dan meningkatkan produksi gambir. Peralatan hidrolik pres mampu melakukan proses pengolahan sebanyak 42 kali perhari dengan hasil perhari $210 \mathrm{~kg}-252 \mathrm{~kg}$, dalam sebulan menghasilkan produksi gambir sebesar 6,3 ton-7,56 ton dengan nilai ekonomi sebesar Rp 277.200.000 sampai Rp 332.640.000,-/bulan.
\end{abstract}

Kata kunci : rekayasa peralatan, inovasi proses, kualitas, kuantitas, dan nilai ekonomi

\begin{abstract}
Gambier processing in West Sumatra initially used Kampo equipment in extracting gambier, Kampo equipment drained a lot of labor, processing in a maximum of 4 times a day, with a yield of 8 - 9\% gambier, in a day only able to produce gambier amounting to $14 \mathrm{~kg}-16 \mathrm{~kg}$. Engineering hydraulic equipment for gambier so that workers do not drain energy, processing can be done more than 20 times, with a rendering above $10 \%$. Hydraulic equipment that is designed to use $H$ frame steel material produces results to ease labor, speed up processing, produce gambier products that are of constant quality and increase gambier production. Hydraulic equipment capable of making processing 42 times per day with daily yields of $210 \mathrm{~kg}-252 \mathrm{~kg}$, in producing gambier production of 6.3 tons - 7.56 tons with an economic value of Rp. $277,200,000$ to Rp. 332,640,000/month.
\end{abstract}

Keywords : Engineering equipment, innovation proccess, quality, quantity, and economic value.

\section{PENDAHULUAN}

Gambir adalah sari getah yang diekstrasi dari daun tanaman gambir dengan cara pengepresan. (Amos, 2010) Gambir dihasilkan dari Indonesia akan tetapi pemanfaatan dalam di Indonesia masih dalam skala usaha kecil menengah.

Pemanfaatan gambir lebih luas sudah sejak lama dikembangkan di Cina, Singapura, Jepang, India dan sekarang sedang tahap penelitian dikembangkan pemanfaatannya di negeri Belanda dan Jerman (Said dkk, 2010).

Gambir di Sumatera Barat, pengolahannya masih dilakukan secara tradisional dengan peralatan pengolahan yang sederhana yang di sebut kampo gambir, memerlukan tenaga manusia yang sangat besar dan waktu pengolahan yang lama, sehingga menyebabkan pengolahannya menjadi kurang optimal (Dhalimi, 2006).

Untuk memenuhi dan menjaga kepercayaan pasar ekspor dibutuhkan 
kestabilan kuantitas dan kualitas gambir (Evalia dkk, 2012).

Pengolahan tradisional, dilakukan di dalam rumah "Kampo" dan masih terdapat beberapa kendala yang harus segera ditangani sehingga proses produksi dapat berlangsung dengan baik dan produk yang dihasilkan mempunyai mutu dan jumlah yang maksimal (Sa'id dkk, 2010).

Kendala-kendala yang jadi masalah penggunaan alat Kampo diantaranya adalah:

1. Banyak menguras tenaga.

2. Waktu pengerjaan (pengepresan) yang cukup lama.

3. Peralatan mudah rusak, karena menggunakan konstruksi kayu.

4. Bahan kayu gelondongan/balok sebagai bahan konstruksi mulai sulit didapat.

Untuk dapat menghasilkan produksi gambir yang meningkat kuantitasnya dalam waktu yang singkat maka perlu dirancang mesin pres menggunakan sistem hidrolik (Amos dkk, 2004).

Alat rekayasa pres gambir agar dapat digunakan maka beberapa hal harus diperhatikan:

1. Pengoperasiannya lebih mudah karena mesin pres dirancang dapat dioperasikan siapa saja.

2. Perawatannya (maintenance) lebih mudah, alat dirancang sederhana dan semua komponennya ada dipasaran.

3. Meningkatkan sumber daya manusia menuju kepada kemandirian Industri dalam negeri.

4. Proses ekstraksi gambir dapat dilakukan dalam waktu singkat, mampu melakukan pengolahan lebih dari 20 kali dalam sehari.

\section{Pengolahan} menentukan kuantitasnya (Manalu dkk, 2019), sehingga perlu dikembangkan peralatan pengolah gambir yang dapat menghasilkan produk gambir yang konsisten kualitas dan kuantitasnya juga ketersediaan produk pada waktu yang tepat.

\section{BAHAN DAN METODE}

Maksud dari rekayasa peralatan pres hidrolik adalah menghasilkan peralatan pres hidrolik yang mampu meringankan dan mempermudah kerja petani gambir, konsistensi kualitas dan kuantitas gambir, mempercepat proses ekstraksi gambir.

\section{Bahan}

Hirolik, shelll, plat H-beam, tabung hidrolik, kertas gambar, baut, bahan las, daun gambir dan air.

\section{Peralatan}

Alat las, alat potong $\mathrm{H}$-Beam, komputer untuk desain, dan peralatan perbengkelan yang sederhana

\section{Metode Penelitian}

Metodologi penelitian ini adalah metode kualitatif studi kasus, meneliti proses pengolahan gambir di Sumatera Barat dengan mengumpulkan data pengolahan yang dilakukan secara turun temurun dan mencarikan solusi yang tepat pengolahan gambir yang efisien, tidak mengeluarkan tenaga manusia dan peningkatkan kuantitas produk gambir/hari.

\section{HASIL DAN PEMBAHASAN}

Pengolahan gambir di Sumatera Barat yang telah dilakukan sejak awal pengolahan gambir menggunakan peralatan "kampo", yang sangat banyak menguras tenaga kerja dan lokasi rumah pengolahan yang jauh dari pemukiman (Sabami, 2015).

Tahapan-tahapan pengolahan gambir dilakukan sebagai berikut:

Daun gambir dan rantingnya dipotong, dimasukkan ke dalam keranjang, dipadatkan dan selanjutnya dengan rata-rata berat daun $50 \mathrm{Kg}$, direbus dalam kuali yang sudah dibersihkan damar agar kuali tidak luntur, air yang dibutuhkan dengan merebus 40- 
60 liter selama 1,5 jam selanjutnya dipres dengan pres tradisional sepeti pada Gambar 1, ekstrak yang diperoleh diendapkan semalam (24 jam), dicetak dan dijemur dengan bantuan sinar matahari selama 3 hari, dihasilkan gambir.

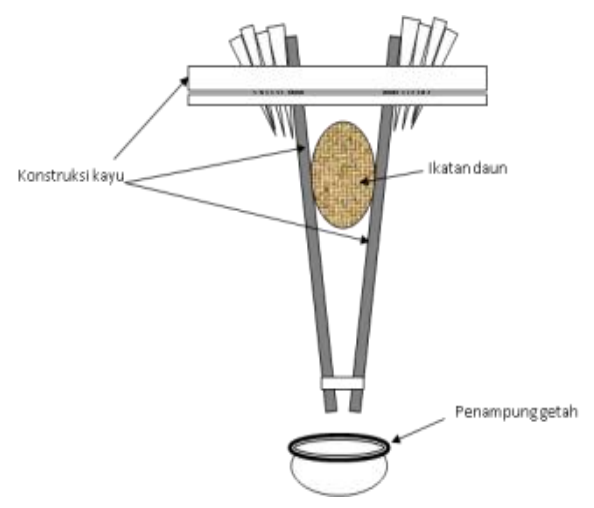

Gambar 1. Peralatan Kampo Gambir

Peralatan press hidrolik adalah
sistem hidrolik yang dapat bekerja
secara mandiri dengan menggunakan
pompa yang terletak terpisah untuk
setiap mesin (Indah dan Baehaqi, 2017).
Dalam rekayasa peralatan hidrolik harus memperhatikan antara lain kebocoran fluida, bengkoknya as rod, rusaknya glan karena kontak dengan as rod, rusaknya tabung karena kontak dengan piston, kekuatan seal menahan tekanan yang tidak sesuai dan harga sebuah sistem hidrolik sangatlah mahal (Al Haramain dkk, 2017).

Sumber energi sistim hidrolik terletak pada penggerak pompa, sistem hidrolik perangkat pentransfer atau pengubah energi, menghasilkan gaya untuk melakukan kerja (Kamsar dkk, 2016).

Komponen utama pada Mesin Press Hidrolik ini adalah Dongkrak Hidrolik, Tabung Pengepressan, plat penekan (Piston Pengepress), Handle, Frame dan ruang pengepressan (Indah dan Baehaqi, 2017).

Secara umum peralatan yang digunakan pada sistem hidrolik terdiri atas Sistem pemipaan dan perapat, pompa dan fluida kerja, aktuator hidrolik, sistem kontrol dan perlengkapan pendukung (Priyati dkk, 2015).
Peralatan sistim hidrolik menggunakan sistim pemipaan yang menghubungkan tempat-tempat yang akan dilalui fluida, seperti tangki, sistem kontrol, silinder/piston dan sebagainya (Zhang, 1999).

Mencegah kebocoran selama fluida mengalir diperlukan sistem perapat berupa packing dan sebagainya pada tempat-tempat tertentu yang dialiri fluida (Dewanto dan Irmawati, 2013).

Pompa memberi takanan yang besar agar untuk mengatasi gaya yang berlawanan dengan fluida akan berfungsi untuk menciptakan aliran fluida dengan cara memindahkan atau mengalirkan sejumlah volume fluida yang menghasilkan gaya (Indah dan Baehaqi, 2017).

Sistem kontrol dalam sistem hidrolik berfungsi untuk mengatur arah aliran dan besar tekanan agar peralatan bisa beroperasi dengan aman. Sistem kontrol tersebut biasanya terdiri atas katup-katup pengatur arah dan tekanan. (Dewanto dan Irmawati, 2013).

Filter menjadi bagian yang penting untuk menyaring kotoran yang terbawa oleh fluida selama operasi.

\section{Rancang Bangun Pres Hidrolik Dasar Perancangan}

Rekayasa mesin pres hidrolik gambir ini mengacu pada mesin press yang sudah ada yang telah dikembangkan tim Peneliti Gambir BPPT dan yang dirancang saat ini adalah penyempurnaan dari alat yang sudah direkayasa, seperti kekutan $\mathrm{H}$ beam, wadah mengalirkan produk hasil pres dan kekuatan wadah pengepresan (Lukas, 2019). Hasil rekayasa diharapkan proses pengepresan gambir hanya untuk memperoleh hasil ekstraksi gambir yang maksimal waktu pengepresan gambir lebih pendek dan kapasitas pres gambir perharinya meningkat.

\section{Perancangan Konstruksi}

Perancangan konstruksi dibuat sekaku mungkin untuk menghindari terjadinya defleksi. Mesin pres hidrolik gambir ini terdiri dari 1 buah aktuator yaitu satu aktuator untuk punch. 
Pemasangan aktuator pada konstruksi dihubungkan dengan menggunakan mur-baut agar mudah dalam pemeliharaan atau penggantian komponen yang rusak.

\section{Konstruksi}

Untuk rangka konstruksi digunakan profil konstruksi baja $\mathrm{H}$ beam dengan ukuran $150 \times 150$. Panjang profilnya $3000 \mathrm{~mm}$. Dapat dilihat pada gambar 2.

Gambar 2. Profil Konstruksi Baja H Beam

\section{Meja Press}

Terbuat dari baja dan permukaan atasnya dilapisi dengan stainles steel. Meja press ini juga berfungsi sebagai tempat meletakkan gambir serta mengaliri air hasil ekstrasi gambir. Meja terbuat dari plat baja dengan tebal 20 $\mathrm{mm}$ jumlahnya 2 buah sehingga tebal Plat baja ini ada $40 \mathrm{~mm}$, plat yang pertama ditengahnya dibuat lingkaran dengan diameter 500 mm, kemudian dibuat untuk aliran air hasil ekstra gambir dengan lebar $300 \mathrm{~mm}$. Untuk ukuran plat panjang dan lebarnya adalah $800 \mathrm{~mm} x$ $800 \mathrm{~mm}$, setiap sisi-sisi plat dipotong berbentuk segi empat dengan ukuran $150 \mathrm{~mm} \times 150 \mathrm{~mm}$ yang berfungsi sebagai tempat konstruksi atau kaki yang terbuat dari profil baja $\mathrm{H}$ beam. Setiap pinggir meja pasang plat tipis dengan tinggi $50 \mathrm{~mm}$ yang difungsikan sebagai penahan air hasil presan agar tidak keluar dari meja presan, seperti pada Gambar 3.

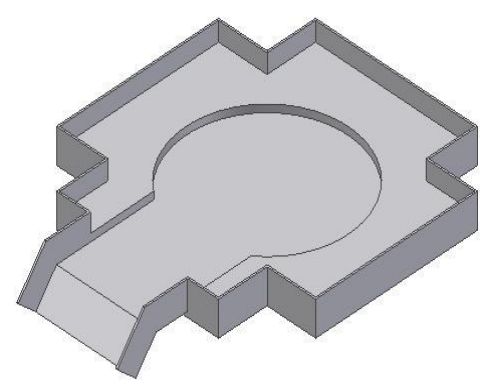

Gambar 3. Meja Press Daun Gambir

\section{Konstruksi Atas}

Konstruksi atas pada mesin press ini berfungsi untuk berdirinya aktuator. Konstruksi mempunyai sisi yang disambung dengan profil baja $\mathrm{H}$ beam, dipasang tulang sebagai penguat. Pada Gambar 4. dapat dilihat bahwa ditengahnya terdapat lubang dengan diameter $230 \mathrm{~mm}$, dipasang aktuator. Konstruksi atas adalah plat baja dengan tebal $20 \mathrm{~mm}$, dimensi plat adalah 500 $\mathrm{mm} \times 500 \mathrm{~mm}$ dengan adanya di setiap sisinya baja profil $\mathrm{H}$ beam maka panjang dan lebarnya menjadi $800 \mathrm{~mm}$ x 800 $\mathrm{mm}$.

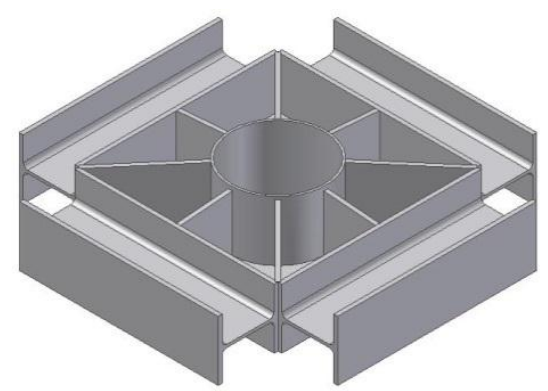

Gambar 4. Konstruksi Atas Mesin Press Gambir

\section{Aktuator}

Aktuator adalah bagian keluaran untuk mengubah energi fluida yang disuplai menjadi energi kerja yang dimanfaatkan. Sinyal keluaran oleh sistem kontrol dan aktuator bekerja melalui sinyal kontrol melalui elemen kontrol terakhir (Hakim, 2009).

Aktuator pada sistem hidrolik menggunakan sistem double acting, supaya posisi naik dan turunnya lebih mudah kontrolnya (Dewanto dan Irmawati, 2013). Dimensi aktuator berbentuk silinder diameter dalam 200 $\mathrm{mm}$ dan diameter luar $230 \mathrm{~mm}$ jadi tebal silinder ini $15 \mathrm{~mm}$. Panjang silindernya $1315 \mathrm{~mm}$. Untuk gambar aktuator, dapat dilihat Gambar 5. Poros aktuator, panjangnya $1320 \mathrm{~mm}$ berdiameter 100 $\mathrm{mm}$ dan tebal piston $100 \mathrm{~mm}$ berdiameter $200 \mathrm{~mm}$. 


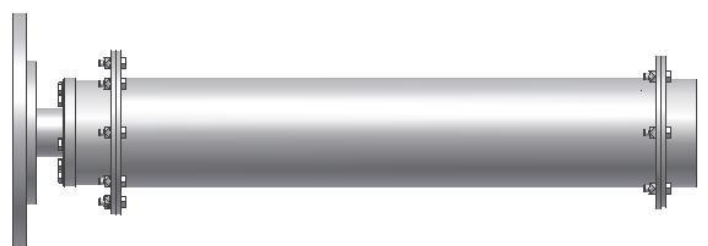

Gambar 5. Aktuator Press Gambir

Perhitungan daya

Spesifikasi mesin yang diinginkan

- Gaya punch (F punch) = 100 ton

- Diameter piston punch $=200 \mathrm{~mm}=$ $0,2 \mathrm{~m}$

- Diameter silinder $=d 200 \mathrm{~mm}=0,2$ $\mathrm{m},=\mathrm{D} 230 \mathrm{~mm}=0,230 \mathrm{~m}$

- Kecepatan press $=0,01 \mathrm{~m} / \mathrm{s}$

- Panjang silinder $=1130 \mathrm{~mm}=1,13 \mathrm{~m}$

Jenis oli yang digunakan untuk hidraulik press gambir ini adalah : SAE 10, karena Viskositas kinematik $=6,34 \times 10^{-6} \mathrm{~m}^{2} / \mathrm{s}$

Tekanan pada piston punch

Gaya punch $=100$ ton $\times 1000 \mathrm{~kg}=$ $100000 \mathrm{~kg} \times 9,81 \mathrm{~m} / \mathrm{s}^{2}=981000 \mathrm{~N}$

$$
\begin{aligned}
& P=\frac{F_{p}}{A_{\text {piston }}} \\
& A_{\text {piston }}=\frac{1}{4} \pi d^{2}=\frac{3,14 \times 0,2^{2}}{4}=0,314 m^{2} \\
& =\frac{981000 \mathrm{~N}}{0,0314 \mathrm{~m}^{2}} \\
& =31242038,22 \mathrm{~Pa} \\
& =31,24 \mathrm{Mpa}
\end{aligned}
$$

\section{Laju aliran oli pada aktuator}

$$
\begin{aligned}
Q_{a k} & =V x A_{\text {piston }} \\
& =0,01 \mathrm{~m} / \mathrm{s} x 0,0314 \mathrm{~m}^{2} \\
& =3,14 x 10^{-4} \mathrm{~m}^{3} / \mathrm{s}
\end{aligned}
$$

Untuk mengubah dari $\mathrm{m}^{3} / \mathrm{s}$ menjadi $\mathrm{l} / \mathrm{m}$ maka:

$3,14 \times 10^{-4} \times 60.000 \mathrm{l} / \mathrm{m}$

$=18,84 \mathrm{l} / \mathrm{m}$

$=4,98 \mathrm{Gpm}$

Untuk laju aliran 4,98 Gpm maka pipa yang dipakai untuk mengaliri fluida ke aktuator adalah ukuran $3 / 4$ " atau $0,01905 \mathrm{~m}$.

$1 \mathrm{~m}^{3} / \mathrm{s}=1000 \mathrm{l} / \mathrm{s}$

$1 \mathrm{~m}^{3} / \mathrm{s}=60.000 \mathrm{l} / \mathrm{m}$
$1 \mathrm{l} / \mathrm{min}=0,2641720524 \mathrm{Gpm}$

1 inch $=0,0254 \mathrm{~m}$

\section{Kecepatan aliran oli}

$$
\begin{aligned}
& Q_{a k}=V_{p i p a} x A_{\text {pipa }} \\
& \begin{aligned}
3,14 \times 10^{-4} \mathrm{~m} / \mathrm{s} & =V_{p i p a} x \frac{\pi}{4}(0,01905) \\
V_{\text {pipa }}=\frac{Q_{a k}}{A_{\text {pipa }}}= & \frac{3,14 \times 10^{-4} \mathrm{~m}^{3} / \mathrm{s}}{\frac{\pi}{4}(0,01905) \mathrm{m}^{2}} \\
& =\frac{0,000314}{2,8488 \times 10^{-4}} \\
& =1,1022 \mathrm{~m} / \mathrm{s}
\end{aligned}
\end{aligned}
$$

Kerugian tekanan akibat gesekan pipa dengan oli

$$
P_{\text {loss }}=\frac{v \cdot L \cdot V \cdot \rho}{d^{2}}
$$

- Untuk pipa 1 (L1) dengan panjang 2,5m

$$
P_{\text {loss }}=\frac{v \cdot L \cdot V \cdot \rho}{d^{2}}
$$

$=$

$\frac{6,34 \times 10^{-6} \mathrm{~m}^{2} / d t \times 2,5 \mathrm{~m} \times 1,1022 \mathrm{~m} / \mathrm{s} \times 873 \mathrm{~kg} / \mathrm{m}^{3}}{0,01905^{2} \mathrm{~m}}$

$$
\begin{aligned}
= & \frac{0,015251 \mathrm{~kg} \frac{\mathrm{m}}{\mathrm{s}}}{0,000363 \mathrm{~m}^{2}} \\
= & 42,014 \mathrm{~N} / \mathrm{m}^{2}
\end{aligned}
$$

- Untuk pipa 2 (L2) dengan panjang $1 \mathrm{~m}$

$$
\begin{aligned}
& P_{\text {loss }}=\frac{v \cdot L \cdot V \cdot \rho}{d^{2}} \\
& =\frac{6,34 \times 10^{-6} \mathrm{~m}^{2} / d t x 1 \mathrm{~m} x 1,1022 \mathrm{~m} / \mathrm{s} x 873 \mathrm{~kg} / \mathrm{m}^{3}}{0,000363 \mathrm{~m}^{2}} \\
& =\frac{0,00610047 \mathrm{~N}}{0,000363 \mathrm{~m}^{2}} \\
& =16,8057 \mathrm{~N} / \mathrm{m}^{2}
\end{aligned}
$$

- Untuk pipa 3 sama dengan pipa 4 (L3 = L4), panjang $2 \mathrm{~m}$

$$
P_{\text {loss }}=\frac{v \cdot L \cdot V \cdot \rho}{d^{2}}
$$




$$
\begin{aligned}
& =\frac{6,34 \times 10^{-6} \mathrm{~m}^{2} / d t \times 2 \mathrm{mx} 1,1022 \mathrm{~m} / \mathrm{s} \times 873 \mathrm{~kg} / \mathrm{m}^{3}}{0,000363 \mathrm{~m}^{3}} \\
& =\frac{0,0122 \mathrm{~N}}{0,000363 \mathrm{~m}^{2}} \\
& =33,611 \mathrm{~N} / \mathrm{m}^{2}
\end{aligned}
$$

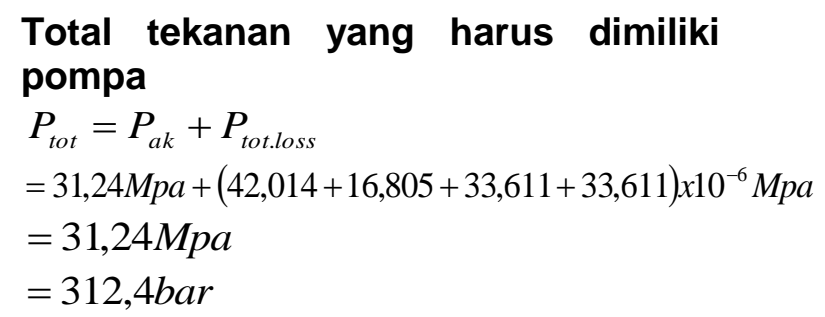

\section{Perhitungan daya fluida}

$$
\begin{aligned}
& \text { Power }=\frac{\text { Pr essure }(\text { bar }) \text { xflow }(l / \mathrm{min})}{612} \\
& \text { Power }=\frac{P \cdot Q}{612} \\
& =\frac{312,4 \text { bar } 18,84 l / \mathrm{min}}{612} \\
& =9,617 \mathrm{~kW}
\end{aligned}
$$

\section{Perhitungan daya pompa}

Jika pompa mempunyai effisiensi $85 \%$ dan putaran 1400rpm maka daya pompanya adalah :

$$
\begin{aligned}
P_{p} & =\frac{P_{f}}{\eta} \\
& =\frac{9,617 \mathrm{~kW}}{85 \%} \\
& =11,31 \mathrm{~kW} \approx 15,37 \mathrm{hp}
\end{aligned}
$$

\section{Diagram Alir Perancangan Sistem Hidrolik}

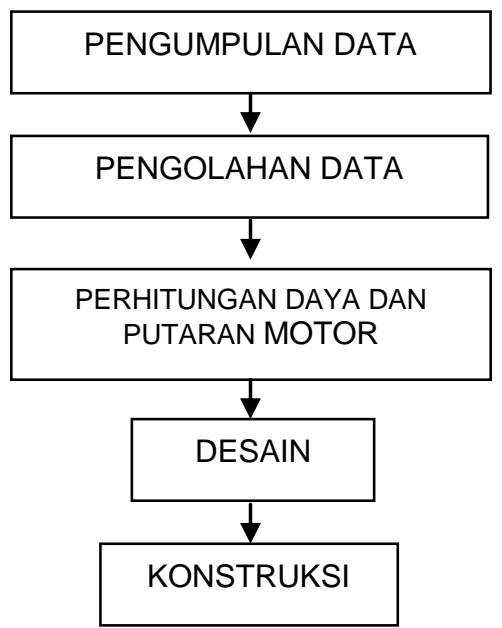

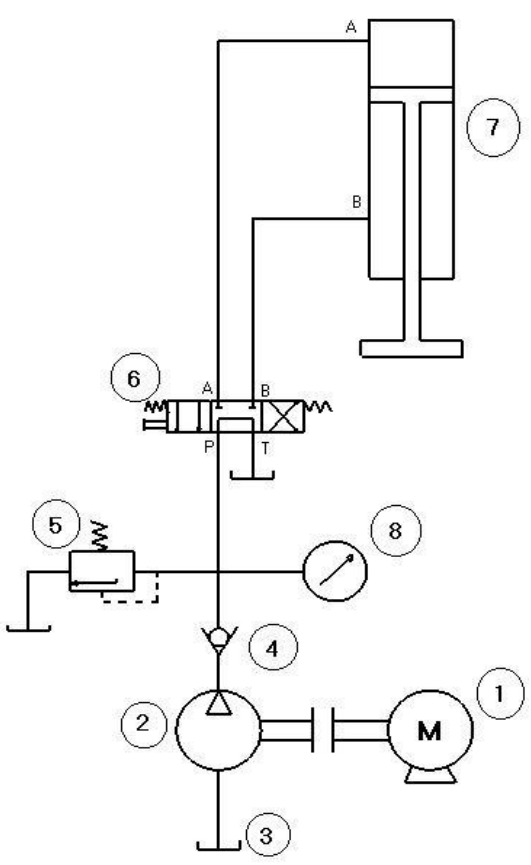

Gambar 6. Diagram Mesin Press

Keterangan Diagram Mesin press gambir

1. Motor : berfungsi sebagai penggerak

2. Pompa : untuk mengalirkan fluida kerja

3. Reservoir (tangki) : sebagai tangki atau tempat fluida kerja

4. Check Valve : katup untuk mengatur arah aliran pada satu arah tertentu yang diinginkan.

5. Relief Valve: berfungsi untuk membatasi tekanan pada harga max tertentu.

6. Handle Valve : katup untuk mengatur arah aliran geser 4 jalur digerakkan secara manual (tangan).

7. Cylinder Hidraulik

8. Pressure Gauge: alat ukur tekanan fluida.

\section{Prinsip Kerja}

Prinsip kerja dari mesin press gambir ini dimulai dengan hidupkan motor listrik, pompa akan dijalankan untuk mengalir oli melalui pipa, proses penekanan dengan mengalirkan oli melalui check valve yang fungsinya untuk mengatur arah aliran pada satu arah tertentu yang diinginkan, setelah melalui check valve kemudian masuk ke relief valve, fungsi dari relief valve ini 
adalah membatasi tekanan. Handle valve yang digerakkan dengan secara manual, handle valve dan relief valve fungsinya hampir sama dan dua komponen ini saling berhubungan. (Wirawan dan Pramono, 2009).

Untuk melakukan penekanan tuas yang ada pada handle valve ditarik ke bawah maka oli akan mengalir ke bagian atas aktuator maka oli akan menekan piston hingga sampai akhir panjang langkah piston yaitu $1000 \mathrm{~mm}$. Oli yang berada di bawah piston tadi akan masuk kereservoir yang diakibatkan adanya penekanan yang dilakukan piston. Begitu juga sebaliknya untuk mengembalikan posisi piston pada posisi yang pertama atau untuk mau melakukan penekanan. Menarik tuas yang ada pada handle valve keatas maka oli akan bergerak dari bawah aktuator dan menekan piston. Oli yang berada pada atas piston akan kembali lagi ke reservoir, begitulah seterusnya untuk cara kerja pada mesin pres hidrolik gambir. Besarnya penekanan hidrolik akan berfungsi mengekstrak sari getah yang ada pada daun gambir.

\section{Pengolahan Gambir Hasil Rekayasa Hirolik Pres}

Pengolahan daun dan ranting gambir menjadi ekstrak sari getah gambir menggunakan peralatan hasil rekayasa hidrolik pres agar diperoleh gambir dengan mutu yang konstan dan kuantitas yang meningkat maka pengolahan dilakukan sebagai berikut:

Memetik daun yang umur 3 bulan dengan warna hijau muda sepanjang 20 $\mathrm{cm}$, dipadatkan dalam keranjang dengan berat 40-59 kg, direbus dengan air sebanyak 40-60 liter pada kuali selama 1,5 jam, diekstraksi dengan press daun dengan peralatan hidrolik hasil rekayasa yang kekuatan tekannya 50 ton per sekali pres yang waktunya 5 menit, hasil ekstraksi dikumpulkan dalam drum dan diaduk merata sampai dipanaskan selama 2 jam pada suhu $40^{\circ} \mathrm{C}$, untuk mengurangi kadar air dan struktur yang teratur pada gambir yang akan dicetak. Hasil ekstraksi dijemur selama 3 hari dengan menggunakan sinar matahari dan gambir yang dihasilkan siap dipasarkan.

\section{Hasil-Hasil Rekayasa Hidrolik Pres}

Dari hasil perancangan, dipilih komponen-komponen yang mendukung pada sistem hidrolik untuk mesin pres gambir pada Tabel 1 berikut :

Tabel 1. Spesifikasi Komponen Pres Gambir

\begin{tabular}{lcc}
\hline Jenis Valve & $\begin{array}{c}\text { Tekanan operasi } \\
\text { maksimum } \\
(\mathrm{Mpa})\end{array}$ & $\begin{array}{c}\mathrm{Q} \\
(\mathrm{I} / \mathrm{min})\end{array}$ \\
\hline Check Valve & 31,24 & 18,84 \\
Relief Valve & 31,24 & 18,84 \\
Handle Valve & 31,24 & 18,84 \\
\hline
\end{tabular}

Untuk komponen pendukung atau aksesoris dapat digunakan:

1. Level Gauges

2. Pressure Gauges

3. Filler Breather Filters (tutup reservoir/tangki)

4. Suction Elements (saringan yang berada di dalam tangki)

Untuk sistem perapat (sealing) pada mesin press gambir ini digunakan:

1. U-Packing seals

2. H-packing seals

3. O-Ring

Pompa yang digunakan untuk mesin press gambir bertekanan maksimum 312,4 bar dengan daya pompa $11,31 \mathrm{~kW}$. Hidrolik power unit ini menggunakan kapasitas oli pada reservoir 150 liter, agar filter oli tidak menyentuh dasar reservoir sehingga kotoran pada oli tidak akan terlalu banyak menyumbat pada filter, agar oli yang di pompa menjadi lancar.

Dalam instalasi sistem hidrolik, baik pipa saluran maupun aktuator harus terisi oli secara penuh tidak boleh ada udara sedikitpun yang terjebak didalam instalasi agar sistem dapat bekerja secara normal. Bila dalam instalasi sistem hidrolik terdapat udara maka mesin press akan bekerja tidak normal dan pengaturan tekanan oli menjadi tidak akurat.

\section{Hasil Produksi Gambir dengan peralatan Hidrolik Press \\ Peralatan hidrolik pres gambir sangat membantu untuk meringankan}


kerja pengolah, meningkatkan kuantitas produksi gambir dengan kualitas yang kontinyu.

Satu peralatan pres hidrolik dapat digunakan untuk kebutuhan 8 tungku perebusan gambir dalam satu rumah kempa, sehingga dalam sehari untuk 8 jam kerja mampu melakukan pengolahan gambir sebanyak 42 kali proses pengolahan, dengan memperhitungkan bongkar pasang peralatan 5 menit sehingga sekali proses memerlukan waktu sebanyak 10 menit, istirahat makan siang 60 menit sehingga waktu bekerja 420 menit dan dibagi 10 menit di hasilkan 42 kali pengolahan.

Perbandingan pres kempa dan hidrolik pada Tabel 2 berikut.

Tabel 2. Perbandingan Pengolahan Tradisional dan Hidrolik Pres

\begin{tabular}{|c|c|c|}
\hline Kinerja & Pres Kempa & Pres Hidrolik \\
\hline $\begin{array}{l}\text { Tenaga kerja } \\
\text { ekstraksi } \\
\text { gambir }\end{array}$ & $\begin{array}{l}\text { Memukul kempa } \\
\text { kayu sehingga } \\
\text { banyak } \\
\text { menguras } \\
\text { tenaga }\end{array}$ & $\begin{array}{l}\text { Secara elektrik, } \\
\text { tenaganya } \\
\text { sangat kecil }\end{array}$ \\
\hline $\begin{array}{l}\text { Waktu pres } \\
\text { Hasil proses } \\
\text { dari berat } \\
\text { daun } 50 \mathrm{~kg}\end{array}$ & $\begin{array}{l}50-60 \text { menit } \\
3,5-4 \mathrm{~kg}\end{array}$ & $\begin{array}{l}4-5 \text { menit } \\
5-6 \mathrm{~kg}\end{array}$ \\
\hline $\begin{array}{l}\text { Tungku } \\
\text { Perebusan }\end{array}$ & 1 buah & 8 buah \\
\hline Tenaga Kerja & 3 orang & 10 orang \\
\hline $\begin{array}{l}\text { Jumlah } \\
\text { olahan/ hari }\end{array}$ & 4 kali & 42 kali \\
\hline $\begin{array}{l}\text { Hasil Gambir/ } \\
\text { hari }\end{array}$ & $14 \mathrm{~kg}-16 \mathrm{~kg}$ & $210 \mathrm{~kg}-252 \mathrm{~kg}$ \\
\hline
\end{tabular}

Peralatan pres hidrolik gambir hasil rekayasa sangat membantu meringankan pekerjaan ekstraksi sari gambir, waktu ekstraksi lebih singkat, jumlah tenaga kerja bertambah dalam satu rumah kempa, jumlah produksi gambir perhari meningkat sampai 200 kali yaitu dari 14-16 kg menjadi 210-252 $\mathrm{kg}$.

Penggunaan peralatan hidrolik press dapat menjamin kesediaan suplay gambir ke konsumen dengan hasil perbulan dengan 1 peralatan bisa mencapai 6,3 ton - 7,56 ton. Dalam satu bulan bisa mensuplai untuk kebutuhan 1 buah kointainer.

\section{Keuntungan Ekonomi Pengunaan Hidrolik Press}

Pengepresan gambir dengan hidrolik dalam sehari dapat menghasilkan $210-252 \mathrm{~kg}$ perhari atau 6,3 ton sampai 7,56 ton perbulan. Menghasilkan pendapatan sebesar Rp. 277.200.000,- sampai Rp 332.640.000,perbulan dengan harga $\mathrm{Rp} 44.000,-/ \mathrm{kg}$.

\section{KESIMPULAN}

Rekayasa peralatan hidrolik pres dapat disimpulkan sebagai berikut :

1. Perancangan konstruksi menggunakan baja profil $\mathrm{H}$ beam, sifat kekakuan dan kekuatan yang lebih besar. $\mathrm{H}$ beam dengan ukuran $150 \mathrm{~mm} \mathrm{X} 150 \mathrm{~mm}$, mampu menanggung gaya penekanan atau beban 100 ton.

2. Perhitungan sistem hidrolik

Daya motor : $11,31 \mathrm{~kW}=15,37 \mathrm{hp}$

Putaran : $1400 \mathrm{rpm}$

Tekanan pada piston punch: $31,24 \mathrm{Mpa}$

Debit oli total : 18,84 l/m

Kecepatan aliran oli : $1,1022 \mathrm{~m} / \mathrm{s}$

Diameter piston punch : $200 \mathrm{~mm}$

3. Untuk silinder hidrolik mesin press gambir ini dimensi sebagai berikut:

Diameter dalam : $200 \mathrm{~mm}$

Diameter luar : $230 \mathrm{~mm}$

Panjang silinder : $1130 \mathrm{~mm}$

Panjang total silinder : $1315 \mathrm{~mm}$

4. Hasil rekayasa peralatan hidrolik pres meringankan beban pekerja, ekstraksi di lakukan dalam waktu 4-5 menit per proses, menghasilkan 5-6 $\mathrm{kg}$ per proses, dalam sehari bisa digunakan untuk 42 kali proses pengolahan dengan 8 tungku perebusan dan menghasilkan 210$252 \mathrm{~kg}$ perhari.

5. Sebulan mampu menghasilkan 6,3 ton sampai 7,56 ton, berkemampuan untuk memenuhi permintaan konsumen dalam waktu yang tepat. Menghasilkan pendapatan sebesar Rp 277.200.000 sampai Rp 332.640.000,- perbulan dengan harga Rp. 44.000,-/kg. 


\section{UCAPAN TERIMA KASIH}

Ucapan terima kasih kepada desa Lubuk Alai, Kabupaten Lima Puluh Kota Sumatera Barat, kelompok tani pengolah gambir, tim peneliti gambir BPPT dan pimpinan yang telah menfasilitasi kegiatan penelitian perekayasaan peralatan hidrolik pres pengolahan gambir.

\section{DAFTAR PUSTAKA}

Al-Haramain, M., Effendi, R. dan Harmanung, A.S. (2017). Perancangan Silinder Hidrolik pada Mesin Molding Karet dengan Kapsitas 25 Ton. Jurnal IImiah Teknik Mesin (SINTEK Jurnal). 11(1).

Amos. (2010). Kandungan Katekin Gambir Sentra Produksi di Indonesia. Jurnal Standarisasi. 12: 149-155.

Amos, Zainuddin, I., Triputranto, A., B. Rusmandana, B. dan Ngudiwaluyo. S. (2004). Teknologi Pasca Panen Gambir. Jakarta: BPPT Press.

Dewanto, A dan Irmawati. D. (2013). Pembelajaran Sistem Hidrolik dan Pneumatik Dengan Menggunakan Automation Studio. Jurnal Pendidikan Teknologi dan Kejuruan. 21(3).

Dhalimi, A. (2006). Permasalahan Gambir (Uncaria gambir L) di Sumatera Barat dan Alternatif Pemecahannya. Perspektif. 5(1).

Evalia, NA, Sa'id, E.G, dan Suryana, R.N. (2012). Strategi Pengembangan Agroindustri dan Pengkajian Nilai Tambah Gambir di Kabupaten Lima Puluh Kota Sumatera Barat. Jurnal Manajemen \& Agribisnis. 9(3): 173-182.

Hakim, L. (2009). Analisa Sistem Pneumartik untuk Penggerak Alat Panen Kelapa Sawit. Jurnal Aptek. 1(1).
Indah, N dan M. Baehaqi. (2017). Desain dan Perancangan Alat Pengepres Gerami Sampah Mesin Perkakas. Jurnal Teknik Mesin. 6(1).

Kamsar., Hasbi, M., dan Rachman, A. (2016). Analisis Sistem Hidrolik Pengangkat pada Alat Berat Jenis Wheel Loader Studi Kasus Dinas Pekerjaan Umum Kab. Bombana. Enthalphy Jurnal IImiah Mahasiswa Teknik Mesin. 1(1).

Lukas, A (2019). Inovasi Teknologi Pengolahan Gambir. Yogyakarta: Kanisius.

Manalu, D.S.T. dan Armayanti, T. (2019). Analisis Nilai Tambah Gambir di Indonesia (Sebuah Tinjauan Literatur). Mahatani. 2(1).

Priyati, A., Ansar dan Sirajuddin H. Abdullah. (2015). Karakteristik dan Simulasi Sisem Kontrol Hidrolik Pada Proses Pengepresan Biji Jarak Kepyar (Ricinus communis L). Jurnal Ilmiah Rekayasa Pertanian dan Biosistem. 3(2).

Sabarni. (2015). Teknik Pembuatan Gambir (Uncaria Gambir Roxb) secara Tradisional. Ekawnie: Jurnal of Islamic Science and Technology. 1(1).

Sa'id, E.G, Syamsu, K., Herryandie. A, Mardliyati, E., Evalia, N.A. (2010). Kajian Perbaikan Mutu pada Agroindustri Skala Mikro dan Kecil Gambir Indonesia. J IImu Pert Indo. 15: 130-136.

Wirawan dan Pramono, (2009). Bahan Ajar Pneumatik-Hidrolik. Semarang: Universitas Negeri Semarang.

Zhang, Q. (1999). Hydraulic Linear Actuator Velocity Control Using A FeedforwardPlus-Pid Control. Department of Agricultural Engineering University of Illinois at Urbana-Champaign, Urbana, IL 61801. Retrieved from https://pdfs.semanticscholar.org/3b8b/97f 7461635335d4546c6e5abf6013735354e. pdf? ga=2.227907675.719382120.1592 $\underline{627342-1225643822.1592627342}$ 